\title{
Magnesium and Cardiovascular Disease
}

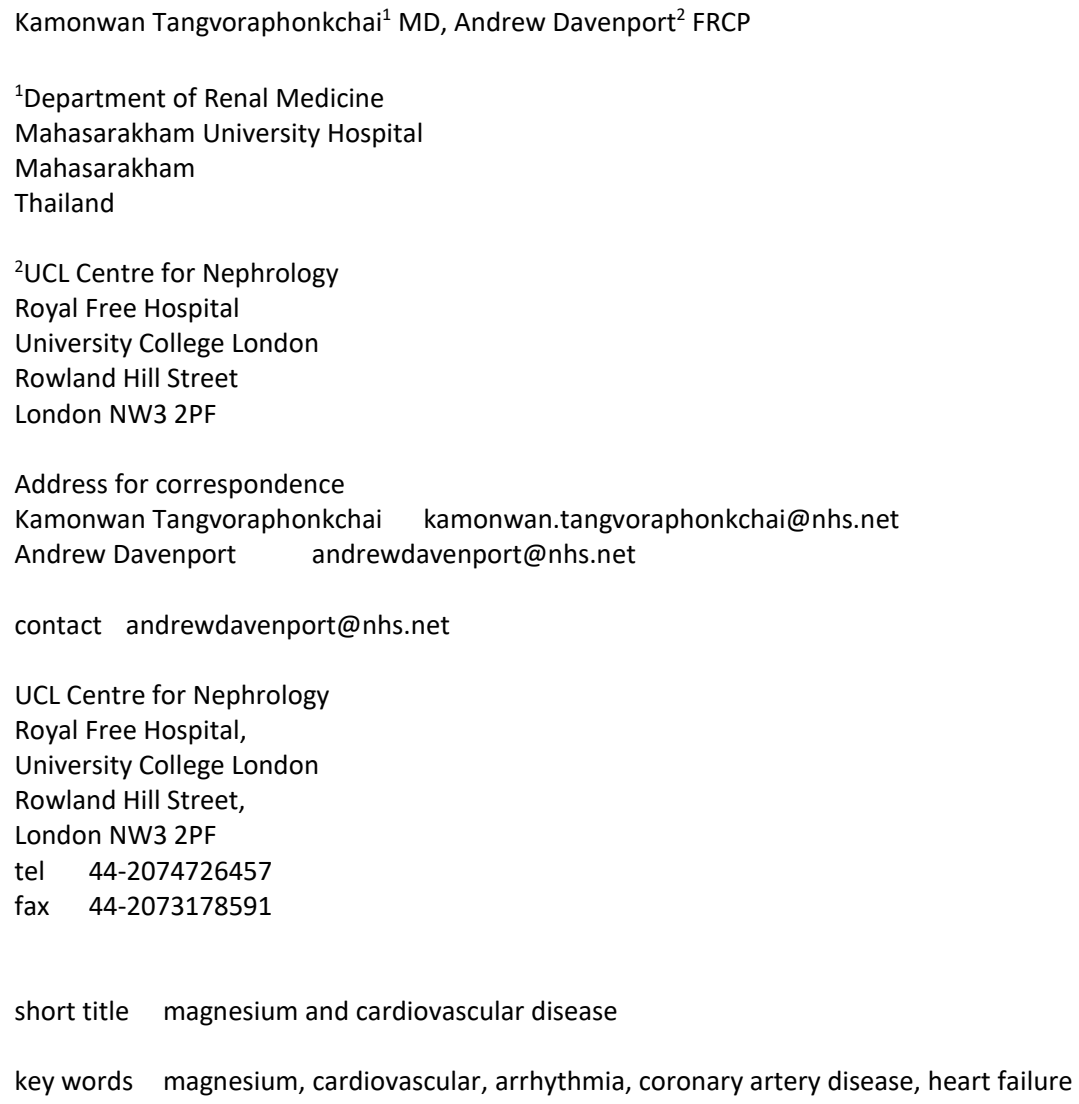

The authors have no conflicts of interest 


\begin{abstract}
Magnesium is the most abundant intracellular divalent cation and essential for maintaining normal cellular physiology and metabolism; acting as a cofactor of numerous enzymes, regulating ion channels and energy generation. In the heart, magnesium plays a key role in modulating neuronal excitation, intra-cardiac conduction, and myocardial contraction by regulating a number of ion transporters, including potassium and calcium channels. Magnesium also has a role in regulating vascular tone, atherogenesis and thrombosis, vascular calcification, proliferation and migration of endothelial and vascular smooth muscle cells. As such, magnesium potentially has a major influence on the pathogenesis of cardiovascular disease.
\end{abstract}

As the kidney is a major regulator of magnesium homeostasis, renal disorders can potentially lead to both magnesium depletion and overload, and as such increase the risk of cardiovascular disease. Observational data have shown an association between low serum magnesium concentrations or magnesium intake and increased atherosclerosis, coronary artery disease, arrhythmias and heart failure. However, major trials of supplementation with magnesium have reported inconsistent benefits and also raised potential adverse effects of magnesium overload. As such, there is currently no firm recommendation for routine magnesium supplementation except when hypomagnesaemia has been proven or suspected as a cause for cardiac arrhythmias.

\title{
Introduction
}

Cardiovascular disease (CVD) has been the leading cause of death globally over past 15 years, and the greatest cause of premature, non-communicable disease deaths. According to the World Health Organization report, ischemic heart disease and stroke accounted for 15 million deaths worldwide in 2015. Despite a declining trend in CVD mortality in high-income countries, there is a growing prevalence of CVD in low- and middle-income nations (1). As such, it is important to determine potentially modifiable risk factors and establishing health promotion programmes which are simple, affordable with applicable strategies.

Magnesium is an essential mineral for human health. The majority of magnesium is intra-cellular and although serum magnesium concentrations may not reflect intracellular magnesium, derangement of serum concentrations can lead to pathology, especially CVD. Growing evidence supports an increased CVD risk with low dietary magnesium intake and a benefit for higher magnesium on the prevention and treatment of CVD (2-4). Whereas mild to moderate magnesium deficiency might increase risk for abnormal cardiac excitation, atherosclerosis, ischaemic heart disease and congestive heart failure, severe magnesium deficiency can cause ventricular dysrhythmias and increase risk of sudden cardiac death. Since magnesium is a key cofactor of many enzymes, changes in intracellular and extracellular concentrations potentially involve in numerous metabolic pathways, especially as magnesium is required for energy (ATP)-dependent reactions. Magnesium also plays a major role in maintaining electrochemical gradients across cytoplasmic membranes, and as such, changes in magnesium concentrations alter membrane potentials and ion transport.

Patients with kidney disease are at risk of magnesium imbalances, as on one hand, a reduction in glomerular filtration rate results in magnesium retention, whereas on the other hand, a variety of disorders of renal tubular handling of magnesium can lead to chronic hypomagnesaemia.

Increasingly, hypomagnesemia can be secondary to drugs including chemotherapeutic agents and diuretics, and gastro-intestinal losses with proton pump inhibitors may all exacerbate magnesium imbalances, and increase risk of cardiovascular complications.

\section{Role of magnesium in the cardiovascular system}


Intracellular magnesium concentrations vary between 5 to $20 \mathrm{mmol} / \mathrm{L}$, depending on tissue type, with the highest concentrations in skeletal and cardiac muscle (5). Within the cell, almost all magnesium is distributed between the nucleus, mitochondria and sarcoplasmic reticulum. Approximately 4-5 mmol/L are in the cytosol, complexed with ATP ( $\mathrm{Mg}^{2+}$-ATP) and other phosphometabolites, with only around $0.5-1.2 \mathrm{mmol} / \mathrm{L}$ freely available (6). Magnesium is important for cellular energy generation, as magnesium-dependent oxidative phosphorylation generates ATP, and all ATP-dependent reactions require magnesium to hydrolyse and transfer phosphate groups. As such, magnesium plays a key role in several metabolic pathways, including glycolysis, DNA synthesis and transcription, protein synthesis, intracellular signalling, regulation of ion channels generating intracellular ion currents and determining membrane voltage (5).

\section{The Heart}

Magnesium exerts effects on cardiac conduction and contraction predominantly by regulating ion channels. Cardiac excitation and automaticity are affected by magnesium modulating potassium and calcium channels and the sodium-potassium ATPase pumps ( $\mathrm{Na} / \mathrm{K}$ ATPase pumps) of cardiac myocytes and pacemaker cells. As such, magnesium regulates membrane potential phases 2,3 , and 4 of cardiac myocytes and phases 0 , and 3 of pacemaker cells (6) as shown in figure 1 and 2 . In phase 0 of the pacemaker cells and phase 2 of cardiac myocytes, both intracellular and extracellular magnesium concentrations control calcium influx into the cells by inhibiting the L-type calcium channels ( $\left.L-I_{C_{a}}\right)(7)$, preventing intracellular calcium overload and cell toxicity (8). This $L-I_{C a}$ modulation depends on magnesium ion concentration and phosphorylation state, as binding of magnesium inhibits the phosphorylated channel from undergoing conformational changes which result in more frequent opening of this channel (9). Acute myocardial infarction and digitalis intoxication are examples of increased cytosol calcium, which then leads to an increased risk for arrhythmia by delayed afterdepolarization (DADs) (figure 3a). In phase 3 , intracellular magnesium concentration controls the outward movement of potassium through inward and delayed rectifier potassium channels $(10,11)$. This regulation is critical for cardiac repolarization and results in prolongation of refractoriness, denoted by long QT intervals on the electrocardiogram (ECG). Prolonged QT intervals, common ECG findings in hypo- and hypermagnesaemia (table 1), can trigger arrhythmias through early afterdepolarization (EADs) (figure 3b). The constant resting membrane potential in phase 4 is maintained by $\mathrm{Na} / \mathrm{K}$ ATPase pump activity and activity of sodium-calcium exchangers (NCX). These active transporters require energy from ATP hydrolysis to translocate sodium and potassium ions counter-currently across the cytoplasmic membrane against their respective concentration gradients, in order to maintain both membrane potential and low cytoplasmic sodium concentrations. Magnesium does not only play a role by ATP formation and hydrolysis, but also by directly driving the opening and closure of the cytoplasmic domains of $\mathrm{Na}^{+} / \mathrm{K}^{+}$ pump (12). Moreover, in this phase, the inward rectification of potassium is modulated by blocking of potassium channel by intracellular magnesium (11).

The effect of magnesium on myocardial contractility is primarily exerted by affecting calcium mobilization. Intracellular calcium is recognized a central role in cardiac excitation-contraction coupling by binding to troponin, so activating myofilaments. In this setting magnesium acts as natural antagonist to calcium by competing with calcium for the binding of troponin $\mathrm{C}$ and calmodulin (13). Moreover, magnesium may directly or indirectly modulate the function of several calcium transporters; calcium ATPase ( $\mathrm{Ca}^{2+}$-ATPase), NCX, L-I $\mathrm{C}_{\mathrm{a}}$ and sarcoplasmic/endoplasmic reticulum calcium ATPase (SERCA), and therefore alters intracellular calcium mobilization from both extracellular fluid and also intracellularly from the sarcoplasmic reticulum.

\section{Blood vessels}


Both extracellular and intracellular magnesium modulate vascular smooth muscle tone by altering cytosolic calcium, which mediates excitation-contraction coupling and actin-myosin crossbridges. Extracellular magnesium blocks calcium influx by inhibiting the calcium current in excitable cells. Neutralizing the negative surface charge of cell membranes by electrostatically binding results in raising the threshold for voltage-gated calcium channels (14). Also, extracellular magnesium may directly bind to calcium channels, which results in either a mechanical block or allosteric modulation of channel gating, leading to an effective closure of channels (15). Intracellular magnesium modulates vascular smooth muscle tone by altering the amplitude, activation/inactivation kinetic and phosphorylation of voltage-dependent $L-I_{C_{a}}$, so decreasing intracellular calcium entry (16). Magnesium also stimulates inositol-1,4,5-triphosphate $\left(\mathrm{IP}_{3}\right)$ breakdown, and as such inhibits $\mathrm{IP}_{3^{-}}$ induced calcium release from the sarcoplasmic reticulum (17); and increases calcium sequestration in the sarcoplasmic reticulum by activating SERCA (18).

Endothelial cells are known to regulate vascular tone and development of local thrombosis and atherogenesis. The endothelium regulates vasomotor tone by synthesizing natural vasodilators; prostacyclin $\left(\mathrm{PGI}_{2}\right)$ and nitric oxide (NO). Extracellular magnesium can increase both $\mathrm{PGI}_{2}$ production and release from endothelial cells (19). Moreover, magnesium also enhances NO synthesis by upregulating endothelial nitric oxide synthase (eNOS) (20). Other reports showed increasing extracellular magnesium concentration blunts vasoconstrictor actions such as the response to endothelin-1 (ET-1) (21) and norepinephrine (22). The effects of hypomagnesaemia induced vasoconstriction are more pronounced when the endothelium is damaged, as contraction is sustained without the transient vasorelaxation phase, in contrast to when the endothelium is intact (23). As such, magnesium could potentially have different effects in the regulation of vascular reactivity, depending on the integrity or damage to the endothelium.

Apart from increasing vascular tone, low magnesium concentrations may inhibit endothelial proliferation and migration (24), and promote endothelial upregulation of the expression of interleukin $1 \beta$ (IL-1ß), interleukin-6 (IL-6), vascular cell adhesion molecule 1 (VCAM-1) and plasminogen activator inhibitor-1 (PAI-1) $(25,26)$, so increasing both prothrombotic and proatherogenic states. Platelet activation is a key factor in the pathogenesis of CAD. Higher Magnesium concentrations have been reported to inhibit ADP-induced P-selectin expression (27), fibrinogenplatelet binding complex (28) and platelet-stimulating factors including thromboxane A2 (TXA2) (29). Moreover, increased magnesium concentrations promote the excretion of platelet-inhibitory factor $\mathrm{PGI}_{2}(30)$ and enhance the cleavage of ultra-large von Willebrand factor (VWF), a prothrombotic glycoprotein (31), so inhibiting both platelet adhesion and aggregation.

Growing evidence has implicated a role for magnesium transporters in CVD. The transient receptor potential melastatin 7 channel (TRPM7) is a ubiquitous magnesium and calcium permeable channel with a fused alpha kinase domain. This cation channel is located on cell membrane of cardiac myocyte and vascular smooth muscle cell, which negatively gated by intracellular magnesium and $\mathrm{Mg}^{2+}$-ATP, as such regulating intracellular magnesium concentrations (32). Some reports have highlighted a role of TRPM7 in cell proliferation, differentiation, migration and embryonic development (33). Vasoactive agents and mechanical stimulants can modulate TRPM7 expression and activity in vascular smooth muscle cells (34). One study observed that aldosterone induced downregulation of TRPM7 which led to increased renal, cardiac, and aortic fibrosis, whereas the administration of magnesium reduced aldosterone-induced cardiovascular and renal injury (35). On the other hand, bradykinin upregulated TRPM7 expression and stimulated its downstream signalling, therefore induced magnesium influx (36). However, whether the interactions of magnesium and 
TRPM7 reported in cell culture experiments, can be transferred into clinical practice awaits elucidation.

TRPM6 a member of transient receptor potential ion channels, is another magnesium transporter located on vascular smooth muscle cells, intestinal epithelium and distal convoluted tubules regulates magnesium influx. In terms of cardiovascular function, TRPM 6 may play a role in determining vasomotor tone and consequently blood pressure regulation by controlling intracellular magnesium concentration (34). However, unlike TRPM 7 which predominantly balances intracellular magnesium, this channel appears to be involved mainly in regulating total body magnesium levels through the kidney and gastrointestinal tract (37). Loss-of-function mutations of the TRPM 6 gene results in hypomagnesemia with secondary hypocalcemia (HSH) due to defective magnesium reabsorption in the kidney. Patients with this genetic defect present with generalized seizures and tetany shortly after birth, or typically during the first month of life, and will suffer from neurological damage or die if left untreated. The solute carrier (SLC) family 41 subtype 1 and 2 (SLC41A1, SLAC41A2, respectively), which are novel magnesium transporters upregulated in the heart under conditions of hypomagnesemia (34). SLC41A1 is a general transporter for divalent cations, and was found to function as sodium/magnesium exchanger which mainly regulates intracellular magnesium homeostasis (38). SLC41A1 knockdown was found to inhibit angiotensin II-induced cardiac fibrosis by preventing magnesium efflux and calcium signalling in cardiac fibroblasts in one animal study (38). Other novel magnesium transporters include Mitochondrial RNA splicing 2 protein (Mrs2p), Magnesium Transporter 1 (MagT1), Ancient Conserved Domain Protein 2 (ACDP2) and Paracellin-1 which are not thought to be located in cardiovascular system. The exact physiological role of these transporters with respect to magnesium homeostasis and cardiovascular disease still awaits clarification.

Vascular calcification reduces aorta and arterial elastance, weakens vasomotor responses and alters atherosclerotic plaque stability, and as such impairs haemodynamics and results in hypertension, aortic stenosis, cardiac hypertrophy, myocardial and lower-limb ischaemia and congestive heart failure (39). Magnesium interferes with the process of vascular calcification by inhibiting the formation of calcium-phosphate apatite by forming magnesium-substituted whitlockite crystals which are smaller and more soluble (40). It also delays the transition from primary calciprotein particles (CPP), the more soluble calcium-phosphate-protein complex to elongated secondary CPP, which are less soluble and prone to deposition (41). Not only inhibiting the entry of calcium into the cells, magnesium enters cells through TRPM 6 and 7 and increases expression of calcification inhibitors including as matrix Gla protein, osteopontin and bone morphogenetic protein (BMP 7); and decreased expression of calcification promoters, such as alkaline phosphatase, BMP2 and runtrelated transcription factor 2 (42), so preventing vascular smooth muscle cells (VSMC) transdifferentiating into osteoblast or chondroblast-like cells.

\section{Cardiovascular morbidity and mortality versus serum magnesium among kidney disease patients}

The prevalence of magnesium imbalances reported vary widely depending on geographical area and clinical conditions, with around $4.6-6.9 \%$ of the population being hypomagnesaemic, and $3 \%$ hypermagnsaemic $(43,44)$. However the prevalence of hypo and hypermagnesaemia significantly increased to $11 \%$ and $9.3 \%$ in hospitalized patients (45), and hypomagnesaemia up to $65 \%$ in intensive care patients (46). As the kidney is a major regulator of magnesium homeostasis, patients with advanced chronic kidney disease (CKD) are vulnerable to magnesium overload. However, there are limited reports of clinically significant effects of high serum magnesium, instead, hypomagnesaemia in pre-dialysis CKD cohorts were reported to increase the rate of deterioration of residual renal function, and increase both cardiovascular and all-cause mortality $(47,48)$. Two large 
observational cohort in haemodialysis reported the greater risk of cardiovascular death in patients with low magnesium concentrations $(48,49)$. Consistently, higher serum magnesium concentration was an independent negative predictor of all-cause and cardiovascular mortality in peritoneal dialysis patients (50).

Congenital renal magnesium wasting, with Barter and Gitelman syndromes were reported to produce prolonged QT intervals on ECG (51), exercise induced myocardial perfusion defects (52), ventricular tachycardia (53) and sudden cardiac death (54). However, it was unclear as to whether the cardiovascular effects were directly as a result of hypomagnesaemia per se (51). Paradoxically, despite hypomagnesaemia, elevated renin, angiotensin II and aldosterone levels, these tubular disorders are not reported to have an increased risk for CVD, hypertension or other CVD risk factors (55). Treatment with antineoplastic agents such as epidermal growth factor receptor (EGFR) antagonists and platinum-based agents may lead to renal tubular magnesium wasting, with cases of malignant arrhythmias reported (56). Hypomagnesaemia is more common in kidney transplant (KT) patients since the era of calcineurin inhibitors. Hypomagnesaemia in KT has been reported to increase arterial stiffness (57) which is a recognised predictor of cardiovascular events in KT patients (58).

\section{Magnesium and cardiovascular disease - evidence for treatment and prevention}

Several observational studies have linked lower serum magnesium concentrations and dietary magnesium intake to the development of CVD and mortality. However, cautious interpretation of these reports should be made due to uncertainty of causal relationship, as the risk of magnesium depletion is greater in patients with additional co-morbidities. For example, severe malnutrition and poor dietary intake are usually manifested in advanced heart failure. Larger dosage of diuretic is also prescribed in this case and leads to greater loss of urinary magnesium and lower serum magnesium levels. Although a number of observational studies have shown positive effects of magnesium-rich diet or magnesium supplementation, well-designed randomized controlled trial which monitors both baseline and followed up magnesium status correlated to clinical outcomes have not been reported. Magnesium supplements typically have gastrointestinal side effects, with diarrhoea being the most common complaint. As such, the amount of oral magnesium that patients can tolerate varies, and patient compliance with magnesium containing medications are potential hurdles that any study has to overcome. More recently a combination of calcium acetate and magnesium carbonate has been introduced to bind phosphate in the gastrointestinal tract for kidney dialysis patients. This combination does not appear to increase gastrointestinal side effects, and does lead to an increase in serum magnesium in dialysis patients, but these patients cannot excrete magnesium in the urine. So whether this effects of this medication applies to patients with normal renal function remains to be determined.

Dietary sources of magnesium include fruits, vegetables, dairy products, and certain grains, which are a key nutrient in the DASH diet (Dietary Approaches to Stop Hypertension). Therefore, it remains controversial whether the advantage reported for cardiovascular disease is an effect of magnesium itself or just consuming healthier, high fibre, less saturated fat diet which usually contains more magnesium. Routine magnesium supplementation should be avoided due to gastrointestinal symptoms leading to non-compliance and metabolic imbalance, unless there are evidences of low serum magnesium level or arrhythmia associated with magnesium depletion.

\section{Atherosclerosis}


Laboratory studies demonstrate the effects of magnesium on platelet activation, vascular tone, endothelial inflammation, proliferation and migration, all of which potentially contribute to atherogenesis. Low dietary intake of magnesium was reported to increase atherosclerotic plaque development in animals (59). Other reports also showed a reduction in atherogenesis and plaque in both LDL-receptor-deficient and Apo-E deficient mice fed with fortified magnesium water $(60,61)$. The population-based Rotterdam Study noted lower serum magnesium concentrations were associated with increased carotid intima-media thickness (62). This finding is consistent with the reports from pre-dialysis CKD patients with high fibroblast growth factor 23 (63) and haemodialysis patients (64), where magnesium supplementation was shown to reduce intima-media thickness (65). Hyperlipidaemia is recognized as a contributor to atherosclerosis and magnesium supplements could reduce triglyceride and very low-density lipoprotein concentrations in both animal and clinical studies $(61,66)$. The reduction of postprandial hyperlipidaemia by magnesium supplementation suggested that magnesium might inhibit gastrointestinal fat absorption (67). One study in predialysis CKD patients showed a strong association between hypomagnesaemia and atherogenic dyslipidaemia (68). Magnesium replacement in KT patients was reported to restore normal serum magnesium concentration and significantly decrease both total cholesterol and low-density lipoprotein (69).

\section{Coronary artery disease}

Low serum magnesium concentrations or low magnesium-intake were reported to associate with CAD in epidemiological studies. By adjusting for other CAD risk factors, the report of The Atherosclerosis Risk in Communities (ARIC) Study showed serum magnesium and low dietary magnesium intake contributed to a greater incidence of CAD (3). The Report of The National Health and Nutrition Examination Survey Epidemiologic Follow up Study also reported that lower serum magnesium was inversely associated with mortality from CAD and all-cause mortality (70). In a 30year follow-up of The Honolulu Heart Program patients who had baseline low dietary magnesium intake, were at 1.5- to 1.8-fold higher risk of CAD (2). More recent population-based study (62) noted that lower serum magnesium concentrations were at increased risk of CAD mortality and sudden cardiac death. Moreover, patients with lower serum magnesium or low dietary magnesium intake had greater left ventricular mass (71) and coronary artery calcification (CAC) $(72,73)$. The effect of lower serum magnesium concentrations increasing CAC is greater for those CKD patients with higher serum phosphate levels (74). Besides cardiovascular pathogenesis, lower serum magnesium is also associated with increased risk of developing the metabolic syndrome (75) and type 2 diabetes mellitus (76) both of which are traditional CAD risk factors.

Magnesium potentially confers cellular protection during myocardial ischaemia by reducing intracellular calcium overload, conserving cellular ATP, reducing myocardial oxygen consumption, attenuating catecholamine-induced elevated oxygen demand and protecting the post-ischemic myocardium from oxidative damage $(7,77)$. Moreover, low extracellular magnesium has been shown to inhibit endothelial migration and proliferation, which adversely affect healing and reendothelialisation, therefore increasing expansion of a myocardial infarct and less collateral vascular development (24). Early in the 1990s, a number of relatively small clinical trials reported a reduction in acute myocardial infarction (AMI) morbidity and mortality by giving magnesium as adjunctive therapy $(78,79)$. However, subsequent three large randomized trials have shown conflicting results. The Second Leicester Intravenous Magnesium Intervention Trial (LIMIT-2) with 2,316 AMI patients yielded reductions in congestive heart failure and both immediate and long-term mortality in those patients given intravenous magnesium $(80,81)$. Whereas, the Fourth International Study of Infarct Survival (ISIS-4) with 58,000 patients did not show any survival-benefit from intravenous magnesium 
sulfate over placebo at 35-day and 1-year (82). However, the time from onset of symptoms to randomization in the latter study was much longer, which could possibly have attenuated any therapeutic effect. Subsequently, the Magnesium in Coronaries (MAGIC) trial involving 6,213 elderly patients reported no benefit for the effect of early magnesium administration on mortality (83). The current conclusions from meta-analysis including three major trials are; high dose ( $\geq 75 \mathrm{mmol}$ ) of magnesium over 24 hours, is unlikely to reduce mortality in patients treated early or late and in patients already receiving thrombolytic therapy, but magnesium may reduce the incidence of ventricular fibrillation, ventricular tachycardia, and severe arrhythmia requiring treatment post AMI (84).

\section{Arrhythmia}

Magnesium physiologically influences cardiac action potentials through ion channels and thereby plays a critical role in the pathogenesis of cardiac arrhythmias. Both hypo- and hypermagnesaemia can lead to fatal arrhythmias as shown in Table 1. However, most studies have concentrated on the effects of hypomagnesaemia, which is often accompanied by hypokalaemia. As magnesium has been shown to reduce automaticity, prolong the atrial, ventricular and atrioventricular nodal conduction period (85), block antegrade and retrograde accessory pathways, and suppress EADs and DADs (7); then the administration of magnesium may be of benefit in the management and prevention of arrhythmias.

Atrial fibrillation (AF) is a common arrhythmia in the general population and sometimes develops due to electrolyte imbalances. Both Framingham Offspring Study and ARIC studies reported a significant association between lower serum magnesium concentrations and the risk of developing $\operatorname{AF}(86,87)$. Meta-analysis of studies using magnesium to treat AF did not show any significant effect on restoring sinus rhythm compared to placebo, although magnesium reduced the fast ventricular response, when used as adjunct to digitalis (88), or combinations of magnesium, potassium, insulin and glucose (89). A more recent randomized controlled trial (RCT) of infusing magnesium in patients undergoing electric cardioversion for chronic AF, also did not show any increased rate of successful cardioversion (90). As such, role of magnesium in the treatment of AF remains controversial.

Arrhythmias are recognized complications post AMI and cardiac surgery, and associated with adverse outcomes. A meta-analysis of intravenous magnesium in patients admitted with AMI showed a $49 \%$ reduction of ventricular tachycardia and fibrillation (91). However, the large RCTs; LIMIT-2, ISIS-4 and MAGIC, did not report any reduction in arrhythmias. Similarly, two other metaanalyses of magnesium administration in the prevention of AF after cardiac surgery reported different outcomes $(92,93)$. Moreover, a recent time-matched analysis study advised against prophylatic magnesium supplementation as higher magnesium levels increased the risk of postoperative AF (94). As such, there are currently no firm recommendations for the use of magnesium to prevent arrhythmia post AMI and cardiac surgery.

Digitalis, an anti-arrhythmic agent, works by inhibiting $\mathrm{Na} / \mathrm{K}$ ATPase pump, so increasing intracellular sodium in phase 4 of the action potential. Retention of intracellular sodium inhibits NCX, results in elevating cytosolic calcium and prolongation of the action potential. Digitalis toxicity induces arrhythmia by increasing DADs and EADs. Magnesium enhances the function of $\mathrm{Na} / \mathrm{K}$ ATPase pumps and antagonizes calcium influx, therefore reversing the effect of digitalis and so preventing digitalis toxicity. One case series reported successful reversal of digitalis-toxic arrhythmia by magnesium administration (95). Additionally, magnesium supplementation potentiated the effect of immunoneutralization of digitalis-like $\mathrm{Na}$ /K-ATPase inhibitors (96). 
Ventricular arrhythmia can be triggered by a prolong QT interval and increasing EADs. Long QT interval can be congenital or acquired. Congenital long QT syndrome (cLQTS) are caused either by autosomal dominant or less often autosomal recessive genetic mutations which encode for abnormal cardiac ion channels. Although role of magnesium supplementation is less important than potassium in CLQTS, there is a strong recommendation to maintain normal serum magnesium concentrations. Acquired long QT syndromes (aLQTS) are usually caused by drug therapy such as antihistamines, antineoplastics and antidepressants, and can be triggered by hypokalemia and hypomagnesemia. Many patients who are found to have QT interval prolongation on ECG recordinhgs are asymptomatic, with only a minority developing palpitations, syncope, or sudden cardiac arrest. Among asymptomatic patients with mild corrected QT interval (QTC) prolongation (< 500 millisecond), exploring the culprit drug or correction of metabolic imbalance can generally be managed as an outpatient. In cases complicated with syncope or ECG signs of instability such as AV block, widening QRS, or marked prolonged QTc (>500 millisecond), then these patients should be admitted for ECG monitoring, withdrawal of the suspected culprit drug, restoration of electrolyte imbalance and treatment of arrhythmias if indicated. Although hypomagnesemia is closely related to QT interval prolongation, routine magnesium administration in asymptomatic aLQTS is not recommended unless there is evidence of hypomagnesemia.

Torsades de pointes (TdP) is a specific ventricular arrhythmia that closely associates with a prolonged QT interval. Although there is no consensus threshold of QT interval prolongation which predicts TdP, there are some reports showing an increased risk when the QTc exceed 500 millisecond (97). Magnesium plays an important role in treatment of TdP, even in patients with normal serum magnesium concentrations (98). Termination of TdP by intravenous magnesium administration might be due to a reduction in the amplitude of EADs by inhibiting calcium influx via L-Ica (99). As a result, EADs are less likely to reach the threshold potential and provoke or sustain $\mathrm{TdP}$. Among patients with TdP who are hemodynamically stable, a 2 gram intravenous bolus of magnesium sulfate ( $4 \mathrm{ml}$ of $50 \%$ solution) mixed with diluent to a total volume of $10 \mathrm{~mL}$ or more is recommended as first-line initial therapy (100). Among patients with TdP who are hemodynamically unstable or become pulseless, prompt treatment with electrical cardioversion/defibrillation is required along with magnesium administration. There is no evidence from randomized studies as to the optimal dose of magnesium sulfate, however, data from case series showed 1-3 grams were effective for TdP termination $(98,101)$.

Proton pumps inhibitors (PPI) are widely used in clinical practice. As these medications inhibit gastrointestinal absorption of magnesium, data from meta-analysis of observational studies has confirmed a significant risk for hypomagnesemia (102). There is a case report of PPI-induced hypomagnesaemia and TdP, successfully terminated by intravenous magnesium (103). Besides TdP, data from Magnesium in Cardiac Arrhythmias (MAGICA) trial demonstrated a significant reduction of frequent ventricular arrhythmia following an increase in magnesium and potassium intake (4). However, the most recent American Heart Association Guidelines for Cardiopulmonary Resuscitation recommended against the routine use of magnesium for ventricular fibrillation or pulseless ventricular tachycardia as magnesium neither increases spontaneous circulation nor improves survival.

\section{Heart failure}

Low serum magnesium concentrations have been implicated in the pathophysiology of heart failure (HF). However, this may be confounded by diuretic therapy as the cause of hypomagnesaemia. Magnesium is an important cofactor for cellular respiration and ATP synthesis in mitochondria, and abnormal magnesium levels might alter energy production of cardiac myocytes. Intracellular

Commented [กต2]: The authors should discuss in greater detail the treatment of long QT syndrome, since this is on elf the only clinical conditions (except for eclampsia) where magnesium is the drug of choice. 
magnesium also mobilizes calcium into sarcoplasmic reticulum where excitation-contraction coupling takes place, so modulating cardiac contraction. Moreover, magnesium can also suppress plasma aldosterone secretion (104), leading to sodium and water retention. As such, hypomagnesaemia might potentially increase the risk of development and progression of HF.

The benefits of magnesium supplementation on treating patients with HF have been reported in many studies. A meta-analysis of prospective cohort studies showed that increasing dietary magnesium intake was associated with a $22 \%$ reduction in the risk of heart HF (105). Moreover, a low dietary magnesium intake $<2.3 \mathrm{mg} / \mathrm{kg}$ increased the risk for subsequent HF hospitalizations in African patients (106). Administration of magnesium showed a decrease in premature ventricular depolarization in patients with class II-IV HF (107). The LIMIT-2 study also reported a $25 \%$ reduction of early left ventricular failure in AMI patients receiving intravenous magnesium (81). However, the prospective PROMISE study of more than 1,000 patients with class III or IV heart failure demonstrated no correlation between serum magnesium and survival (108). Moreover, whereas most studies have reported hypomagnesaemia as a risk factor, serum magnesium of $\geq 1.05 \mathrm{mmol} / \mathrm{L}$ was associated with an increased risk mortality in one study of elderly patients with chronic HF who had reduced left ventricular systolic function (109). In contrast to LIMIT-2 study, the later MAGIC trial found no effect of intravenous magnesium on HF (83). As such, due to the differences in outcomes reported, routine magnesium supplementation is not recommended in patients with HF.

\section{Conclusion}

Magnesium has a key role in the regulating of cardiovascular physiology. Experimental evidence supports a substantial role for both intra- and extracellular magnesium concentrations on contraction, conduction and excitation of cardiac myocytes and pacemaker cells. Moreover, magnesium also plays a role in regulating vascular tone, pathogenesis of atheroma, vasoactive response, vascular calcification, proliferation and migration of endothelial and vascular smooth muscle cells. Observational data supports a role for lower serum magnesium and increased risk for the CVD in both the general population and also CKD patients. However, results from the majority of clinical trials of magnesium supplementation as a treatment for the prevention and treatment of CVD have been equivocal. As such, no clinical guidelines currently support the routine magnesium administration in AMI, HF, arrhythmia treatment and prevention, and cardiovascular resuscitation.

\section{Reference}

1. Organization WH. Global status report on noncommunicable diseases 2014: World Health Organization; 2014.

2. Abbott RD, Ando F, Masaki KH, Tung KH, Rodriguez BL, Petrovitch H, et al. Dietary magnesium intake and the future risk of coronary heart disease (the Honolulu Heart Program). Am J Cardiol. 2003;92(6):665-9.

3. Liao F, Folsom AR, Brancati FL. Is low magnesium concentration a risk factor for coronary heart disease? The Atherosclerosis Risk in Communities (ARIC) Study. Am Heart J. 1998;136(3):480-90. 4. Zehender M, Meinertz T, Faber T, Caspary A, Jeron A, Bremm K, et al. Antiarrhythmic effects of increasing the daily intake of magnesium and potassium in patients with frequent ventricular arrhythmias. Magnesium in Cardiac Arrhythmias (MAGICA) Investigators. J Am Coll Cardiol. 1997;29(5):1028-34.

5. Schrier RW. Atlas of diseases of the kidney. Philadelphia: Current Medicine; 1999.

6. de Baaij JH, Hoenderop JG, Bindels RJ. Magnesium in man: implications for health and disease. Physiol Rev. 2015;95(1):1-46.

7. Kolte D, Vijayaraghavan K, Khera S, Sica DA, Frishman WH. Role of magnesium in cardiovascular diseases. Cardiol Rev. 2014;22(4):182-92. 
8. Wang M, Tashiro M, Berlin JR. Regulation of L-type calcium current by intracellular magnesium in rat cardiac myocytes. J Physiol. 2004;555(Pt 2):383-96.

9. White RE, Hartzell HC. Effects of intracellular free magnesium on calcium current in isolated cardiac myocytes. Science. 1988;239(4841 Pt 1):778-80.

10.Duchatelle-Gourdon I, Hartzell HC, Lagrutta AA. Modulation of the delayed rectifier potassium current in frog cardiomyocytes by beta-adrenergic agonists and magnesium. J Physiol. 1989;415:25174.

11.Ishihara K, Sarai N, Asakura K, Noma A, Matsuoka S. Role of $\mathrm{Mg}(2+)$ block of the inward rectifier $\mathrm{K}(+)$ current in cardiac repolarization reserve: A quantitative simulation. J Mol Cell Cardiol. 2009;47(1):76-84.

12.Grycova L, Sklenovsky P, Lansky Z, Janovska M, Otyepka M, Amler E, et al. ATP and magnesium drive conformational changes of the $\mathrm{Na}+/ \mathrm{K}+-$ ATPase cytoplasmic headpiece. Biochim Biophys Acta. 2009;1788(5):1081-91.

13.Iseri LT, French JH. Magnesium: nature's physiologic calcium blocker. Am Heart J. 1984;108(1):188-93.

14. Khan N, Gray IP, Obejero-Paz CA, Jones SW. Permeation and gating in CaV3.1 (alpha1G) T-type calcium channels effects of $\mathrm{Ca} 2+, \mathrm{Ba}+, \mathrm{Mg} 2+$, and Na+. J Gen Physiol. 2008;132(2):223-38. 15. Lansman JB, Hess P, Tsien RW. Blockade of current through single calcium channels by $\mathrm{Cd} 2+$, $\mathrm{Mg} 2+$, and $\mathrm{Ca} 2+$. Voltage and concentration dependence of calcium entry into the pore. J Gen Physiol. 1986;88(3):321-47.

16.Mubagwa K, Gwanyanya A, Zakharov S, Macianskiene R. Regulation of cation channels in cardiac and smooth muscle cells by intracellular magnesium. Arch Biochem Biophys. 2007;458(1):73-89.

17.Volpe P, Alderson-Lang BH, Nickols GA. Regulation of inositol 1,4,5-trisphosphate-induced Ca2+ release. I. Effect of Mg2+. Am J Physiol. 1990;258(6 Pt 1):C1077-85.

18. Laurant $\mathrm{P}$, Touyz RM. Physiological and pathophysiological role of magnesium in the cardiovascular system: implications in hypertension. J Hypertens. 2000;18(9):1177-91.

19.Satake K, Lee JD, Shimizu H, Uzui H, Mitsuke Y, Yue H, et al. Effects of magnesium on prostacyclin synthesis and intracellular free calcium concentration in vascular cells. Magnes Res. 2004;17(1):20-7. 20. Maier JA, Bernardini D, Rayssiguier Y, Mazur A. High concentrations of magnesium modulate vascular endothelial cell behaviour in vitro. Biochim Biophys Acta. 2004;1689(1):6-12.

21.Laurant $P$, Berthelot $A$. Endothelin-1-induced contraction in isolated aortae from normotensive and DOCA-salt hypertensive rats: effect of magnesium. Br J Pharmacol. 1996;119(7):1367-74.

22.Shimosawa T, Takano K, Ando K, Fujita T. Magnesium inhibits norepinephrine release by blocking $\mathrm{N}$-type calcium channels at peripheral sympathetic nerve endings. Hypertension. 2004;44(6):897902.

23.Gold ME, Buga GM, Wood KS, Byrns RE, Chaudhuri G, Ignarro LJ. Antagonistic modulatory roles of magnesium and calcium on release of endothelium-derived relaxing factor and smooth muscle tone. Circ Res. 1990;66(2):355-66.

24.Banai S, Haggroth L, Epstein SE, Casscells W. Influence of extracellular magnesium on capillary endothelial cell proliferation and migration. Circ Res. 1990;67(3):645-50.

25. Maier JA, Malpuech-Brugere C, Zimowska W, Rayssiguier Y, Mazur A. Low magnesium promotes endothelial cell dysfunction: implications for atherosclerosis, inflammation and thrombosis. Biochim Biophys Acta. 2004;1689(1):13-21.

26. Bernardini D, Nasulewic A, Mazur A, Maier JA. Magnesium and microvascular endothelial cells: a role in inflammation and angiogenesis. Front Biosci. 2005;10:1177-82.

27.Gawaz M, Reininger A, Neumann FJ. Platelet function and platelet-leukocyte adhesion in symptomatic coronary heart disease. Effects of intravenous magnesium. Thromb Res. 1996;83(5):341-9.

28.Gawaz M, Ott I, Reininger AJ, Neumann FJ. Effects of magnesium on platelet aggregation and adhesion. Magnesium modulates surface expression of glycoproteins on platelets in vitro and ex vivo. Thromb Haemost. 1994;72(6):912-8. 
29. Hwang DL, Yen CF, Nadler JL. Effect of extracellular magnesium on platelet activation and intracellular calcium mobilization. Am J Hypertens. 1992;5(10):700-6.

30.Nadler JL, Goodson S, Rude RK. Evidence that prostacyclin mediates the vascular action of magnesium in humans. Hypertension. 1987;9(4):379-83.

31.Dong JF, Cruz MA, Aboulfatova K, Martin C, Choi H, Bergeron AL, et al. Magnesium maintains endothelial integrity, up-regulates proteolysis of ultra-large von Willebrand factor, and reduces platelet aggregation under flow conditions. Thromb Haemost. 2008;99(3):586-93.

32.Paravicini TM, Chubanov V, Gudermann T. TRPM7: a unique channel involved in magnesium homeostasis. Int J Biochem Cell Biol. 2012;44(8):1381-4.

33.Visser D, Middelbeek J, van Leeuwen FN, Jalink K. Function and regulation of the channel-kinase TRPM7 in health and disease. Eur J Cell Biol. 2014;93(10-12):455-65.

34. Touyz RM. Transient receptor potential melastatin 6 and 7 channels, magnesium transport, and vascular biology: implications in hypertension. Am J Physiol Heart Circ Physiol. 2008;294(3):H110318.

35.Sontia B, Montezano AC, Paravicini T, Tabet F, Touyz RM. Downregulation of renal TRPM7 and increased inflammation and fibrosis in aldosterone-infused mice: effects of magnesium. Hypertension. 2008;51(4):915-21.

36.Callera GE, He Y, Yogi A, Montezano AC, Paravicini T, Yao G, et al. Regulation of the novel Mg2+ transporter transient receptor potential melastatin 7 (TRPM7) cation channel by bradykinin in vascular smooth muscle cells. J Hypertens. 2009;27(1):155-66.

37.Yogi A, Callera GE, Antunes TT, Tostes RC, Touyz RM. Vascular biology of magnesium and its transporters in hypertension. Magnes Res. 2010;23(4):S207-15.

38. Yu N, Jiang J, Yu Y, Li H, Huang X, Ma Y, et al. SLC41A1 knockdown inhibits angiotensin Il-induced cardiac fibrosis by preventing $\mathrm{Mg}(2+)$ efflux and $\mathrm{Ca}(2+)$ signaling in cardiac fibroblasts. Arch Biochem Biophys. 2014;564:74-82.

39. Demer LL, Tintut Y. Vascular calcification: pathobiology of a multifaceted disease. Circulation. 2008;117(22):2938-48.

40.Cheng PT, Grabher JJ, LeGeros RZ. Effects of magnesium on calcium phosphate formation. Magnesium. 1988;7(3):123-32.

41.Pasch A, Farese S, Graber S, Wald J, Richtering W, Floege J, et al. Nanoparticle-based test measures overall propensity for calcification in serum. J Am Soc Nephrol. 2012;23(10):1744-52. 42. Montezano AC, Zimmerman D, Yusuf H, Burger D, Chignalia AZ, Wadhera V, et al. Vascular smooth muscle cell differentiation to an osteogenic phenotype involves TRPM7 modulation by magnesium. Hypertension. 2010;56(3):453-62.

43. Syedmoradi L, Ghasemi A, Zahediasl S, Azizi F. Prevalence of hypo- and hypermagnesemia in an Iranian urban population. Ann Hum Biol. 2011;38(2):150-5.

44.Whang R, Hampton EM, Whang DD. Magnesium homeostasis and clinical disorders of magnesium deficiency. Ann Pharmacother. 1994;28(2):220-6.

45.Wong ET, Rude RK, Singer FR, Shaw ST, Jr. A high prevalence of hypomagnesemia and hypermagnesemia in hospitalized patients. Am J Clin Pathol. 1983;79(3):348-52.

46. Ryzen E. Magnesium homeostasis in critically ill patients. Magnesium. 1989;8(3-4):201-12.

47. Kanbay M, Yilmaz MI, Apetrii M, Saglam M, Yaman H, Unal HU, et al. Relationship between serum magnesium levels and cardiovascular events in chronic kidney disease patients. Am J Nephrol. 2012;36(3):228-37.

48.Sakaguchi Y, Fujii N, Shoji T, Hayashi T, Rakugi H, Isaka Y. Hypomagnesemia is a significant predictor of cardiovascular and non-cardiovascular mortality in patients undergoing hemodialysis. Kidney Int. 2014;85(1):174-81.

49. Lacson E, Jr., Wang W, Ma L, Passlick-Deetjen J. Serum Magnesium and Mortality in Hemodialysis Patients in the United States: A Cohort Study. Am J Kidney Dis. 2015;66(6):1056-66.

50.Cai K, Luo Q, Dai Z, Zhu B, Fei J, Xue C, et al. Hypomagnesemia Is Associated with Increased Mortality among Peritoneal Dialysis Patients. PLoS One. 2016;11(3):e0152488. 
51.Bettinelli A, Tosetto C, Colussi G, Tommasini G, Edefonti A, Bianchetti MG. Electrocardiogram with prolonged QT interval in Gitelman disease. Kidney Int. 2002;62(2):580-4.

52.Scognamiglio R, Calo LA, Negut C, Coccato M, Mormino P, Pessina AC. Myocardial perfusion defects in Bartter and Gitelman syndromes. Eur J Clin Invest. 2008;38(12):888-95.

53.Pachulski RT, Lopez F, Sharaf R. Gitelman's not-so-benign syndrome. N Engl J Med.

2005;353(8):850-1.

54.Scognamiglio R, Negut C, Calo LA. Aborted sudden cardiac death in two patients with Bartter's/Gitelman's syndromes. Clin Nephrol. 2007;67(3):193-7.

55.Calo LA. Vascular tone control in humans: insights from studies in Bartter's/Gitelman's syndromes. Kidney Int. 2006;69(6):963-6.

56. Velimirovic M, Ziperstein JC, Fenves AZ. A case of chronic hypomagnesemia in a cancer survivor. Hosp Pract (1995). 2017;45(2):58-64.

57.Van Laecke S, Marechal C, Verbeke F, Peeters P, Van Biesen W, Devuyst O, et al. The relation between hypomagnesaemia and vascular stiffness in renal transplant recipients. Nephrol Dial Transplant. 2011;26(7):2362-9.

58.Verbeke F, Marechal C, Van Laecke S, Van Biesen W, Devuyst O, Van Bortel LM, et al. Aortic stiffness and central wave reflections predict outcome in renal transplant recipients. Hypertension. 2011;58(5):833-8.

59. King JL, Miller RJ, Blue JP, Jr., O'Brien WD, Jr., Erdman JW, Jr. Inadequate dietary magnesium intake increases atherosclerotic plaque development in rabbits. Nutr Res. 2009;29(5):343-9. 60.Sherer Y, Shoenfeld Y, Shaish A, Levkovitz H, Bitzur R, Harats D. Suppression of atherogenesis in female low-density lipoprotein receptor knockout mice following magnesium fortification of drinking water: the importance of diet. Pathobiology. 2000;68(2):93-8.

61.Ravn HB, Korsholm TL, Falk E. Oral magnesium supplementation induces favorable antiatherogenic changes in ApoE-deficient mice. Arterioscler Thromb Vasc Biol. 2001;21(5):858-62. 62. Kieboom BC, Niemeijer MN, Leening MJ, van den Berg ME, Franco OH, Deckers JW, et al. Serum Magnesium and the Risk of Death From Coronary Heart Disease and Sudden Cardiac Death. J Am Heart Assoc. 2016;5(1).

63.Silva AP, Gundlach K, Buchel J, Jeronimo T, Fragoso A, Silva C, et al. Low Magnesium Levels and FGF-23 Dysregulation Predict Mitral Valve Calcification as well as Intima Media Thickness in Predialysis Diabetic Patients. Int J Endocrinol. 2015;2015:308190.

64.Tzanakis I, Virvidakis K, Tsomi A, Mantakas E, Girousis N, Karefyllakis N, et al. Intra- and extracellular magnesium levels and atheromatosis in haemodialysis patients. Magnes Res. 2004;17(2):102-8.

65.Turgut F, Kanbay M, Metin MR, Uz E, Akcay A, Covic A. Magnesium supplementation helps to improve carotid intima media thickness in patients on hemodialysis. Int Urol Nephrol. 2008;40(4):1075-82.

66. Rasmussen HS, Aurup P, Goldstein K, McNair P, Mortensen PB, Larsen OG, et al. Influence of magnesium substitution therapy on blood lipid composition in patients with ischemic heart disease A double-blind, placebo controlled study. Arch Intern Med. 1989;149(5):1050-3.

67. Kishimoto $\mathrm{Y}$, Tani M, Uto-Kondo H, Saita E, lizuka M, Sone H, et al. Effects of magnesium on postprandial serum lipid responses in healthy human subjects. Br J Nutr. 2010;103(4):469-72. 68. Dey R, Rajappa M, Parameswaran S, Revathy G. Hypomagnesemia and atherogenic dyslipidemia in chronic kidney disease: surrogate markers for increased cardiovascular risk. Clin Exp Nephrol. 2015;19(6):1054-61.

69.Gupta BK, Glicklich D, Tellis VA. Magnesium repletion therapy improved lipid metabolism in hypomagnesemic renal transplant recipients: a pilot study. Transplantation. 1999;67(11):1485-7. 70.Ford ES. Serum magnesium and ischaemic heart disease: findings from a national sample of US adults. Int J Epidemiol. 1999;28(4):645-51. 
71.Reffelmann T, Dorr M, Ittermann T, Schwahn C, Volzke H, Ruppert J, et al. Low serum magnesium concentrations predict increase in left ventricular mass over 5 years independently of common cardiovascular risk factors. Atherosclerosis. 2010;213(2):563-9.

72.Posadas-Sanchez R, Posadas-Romero C, Cardoso-Saldana G, Vargas-Alarcon G, Villarreal-Molina MT, Perez-Hernandez N, et al. Serum magnesium is inversely associated with coronary artery calcification in the Genetics of Atherosclerotic Disease (GEA) study. Nutr J. 2016;15:22.

73. Hruby A, O'Donnell CJ, Jacques PF, Meigs JB, Hoffmann U, McKeown NM. Magnesium intake is inversely associated with coronary artery calcification: the Framingham Heart Study. JACC Cardiovasc Imaging. 2014;7(1):59-69.

74.Sakaguchi Y, Hamano T, Nakano C, Obi Y, Matsui I, Kusunoki Y, et al. Association between Density of Coronary Artery Calcification and Serum Magnesium Levels among Patients with Chronic Kidney Disease. PLoS One. 2016;11(9):e0163673.

75. He K, Liu K, Daviglus ML, Morris SJ, Loria CM, Van Horn L, et al. Magnesium intake and incidence of metabolic syndrome among young adults. Circulation. 2006;113(13):1675-82.

76. Kao WH, Folsom AR, Nieto FJ, Mo JP, Watson RL, Brancati FL. Serum and dietary magnesium and the risk for type 2 diabetes mellitus: the Atherosclerosis Risk in Communities Study. Arch Intern Med. 1999;159(18):2151-9.

77.Dickens BF, Weglicki WB, Li YS, Mak IT. Magnesium deficiency in vitro enhances free radicalinduced intracellular oxidation and cytotoxicity in endothelial cells. FEBS Lett. 1992;311(3):187-91. 78. Rasmussen HS, McNair P, Norregard P, Backer V, Lindeneg O, Balslev S. Intravenous magnesium in acute myocardial infarction. Lancet. 1986;1(8475):234-6.

79. Shechter M, Hod H, Marks N, Behar S, Kaplinsky E, Rabinowitz B. Beneficial effect of magnesium sulfate in acute myocardial infarction. Am J Cardiol. 1990;66(3):271-4.

80. Woods KL, Fletcher S, Roffe C, Haider Y. Intravenous magnesium sulphate in suspected acute myocardial infarction: results of the second Leicester Intravenous Magnesium Intervention Trial (LIMIT-2). Lancet. 1992;339(8809):1553-8.

81.Woods KL, Fletcher S. Long-term outcome after intravenous magnesium sulphate in suspected acute myocardial infarction: the second Leicester Intravenous Magnesium Intervention Trial (LIMIT2). Lancet. 1994;343(8901):816-9.

82.ISIS-4: a randomised factorial trial assessing early oral captopril, oral mononitrate, and intravenous magnesium sulphate in 58,050 patients with suspected acute myocardial infarction. ISIS4 (Fourth International Study of Infarct Survival) Collaborative Group. Lancet. 1995;345(8951):66985.

83. Magnesium in Coronaries Trial I. Early administration of intravenous magnesium to high-risk patients with acute myocardial infarction in the Magnesium in Coronaries (MAGIC) Trial: a randomised controlled trial. Lancet. 2002;360(9341):1189-96.

84.Li J, Zhang Q, Zhang M, Egger M. Intravenous magnesium for acute myocardial infarction. Cochrane Database Syst Rev. 2007(2):CD002755.

85. DiCarlo LA, Jr., Morady F, de Buitleir M, Krol RB, Schurig L, Annesley TM. Effects of magnesium sulfate on cardiac conduction and refractoriness in humans. J Am Coll Cardiol. 1986;7(6):1356-62. 86. Khan AM, Lubitz SA, Sullivan LM, Sun JX, Levy D, Vasan RS, et al. Low serum magnesium and the development of atrial fibrillation in the community: the Framingham Heart Study. Circulation. 2013;127(1):33-8.

87. Misialek JR, Lopez FL, Lutsey PL, Huxley RR, Peacock JM, Chen LY, et al. Serum and dietary magnesium and incidence of atrial fibrillation in whites and in African Americans--Atherosclerosis Risk in Communities (ARIC) study. Circ J. 2013;77(2):323-9.

88. Ho KM, Sheridan DJ, Paterson T. Use of intravenous magnesium to treat acute onset atrial fibrillation: a meta-analysis. Heart. 2007;93(11):1433-40

89.Ingemansson MP, Smideberg B, Olsson SB. Intravenous MgSO4 alone and in combination with glucose, insulin and potassium (GIK) prolong the atrial cycle length in chronic atrial fibrillation. Europace. 2000;2(2):106-14. 
90. Rajagopalan B, Shah Z, Narasimha D, Bhatia A, Kim CH, Switzer DF, et al. Efficacy of Intravenous Magnesium in Facilitating Cardioversion of Atrial Fibrillation. Circ Arrhythm Electrophysiol.

2016;9(9).

91.Horner SM. Efficacy of intravenous magnesium in acute myocardial infarction in reducing arrhythmias and mortality. Meta-analysis of magnesium in acute myocardial infarction. Circulation. 1992;86(3):774-9.

92.Arsenault KA, Yusuf AM, Crystal E, Healey JS, Morillo CA, Nair GM, et al. Interventions for preventing post-operative atrial fibrillation in patients undergoing heart surgery. Cochrane Database Syst Rev. 2013(1):CD003611.

93.Cook RC, Yamashita MH, Kearns M, Ramanathan K, Gin K, Humphries KH. Prophylactic magnesium does not prevent atrial fibrillation after cardiac surgery: a meta-analysis. Ann Thorac Surg. 2013;95(2):533-41.

94.Lancaster TS, Schill MR, Greenberg JW, Moon MR, Schuessler RB, Damiano RJ, Jr., et al. Potassium and Magnesium Supplementation Do Not Protect Against Atrial Fibrillation After Cardiac Operation: A Time-Matched Analysis. Ann Thorac Surg. 2016;102(4):1181-8.

95.Cohen L, Kitzes R. Magnesium sulfate and digitalis-toxic arrhythmias. JAMA. 1983;249(20):280810.

96.Zazerskaya IE, Ishkaraeva VV, Frolova EV, Solodovnikova NG, Grigorova YN, David Adair C, et al. Magnesium sulfate potentiates effect of DigiFab on marinobufagenin-induced $\mathrm{Na} / \mathrm{K}$-ATPase inhibition. Am J Hypertens. 2013;26(11):1269-72.

97.Priori SG, Schwartz PJ, Napolitano C, Bloise R, Ronchetti E, Grillo M, et al. Risk stratification in the long-QT syndrome. N Engl J Med. 2003;348(19):1866-74.

98.Tzivoni D, Banai S, Schuger C, Benhorin J, Keren A, Gottlieb S, et al. Treatment of torsade de pointes with magnesium sulfate. Circulation. 1988;77(2):392-7.

99. Kaye P, O'Sullivan I. The role of magnesium in the emergency department. Emerg Med J. 2002;19(4):288-91.

100. Neumar RW, Otto CW, Link MS, Kronick SL, Shuster M, Callaway CW, et al. Part 8: adult advanced cardiovascular life support: 2010 American Heart Association Guidelines for Cardiopulmonary Resuscitation and Emergency Cardiovascular Care. Circulation. 2010;122(18 Supp 3):S729-67.

101. Etienne Y, Blanc JJ, Songy B, Boschat J, Guiserix J, Etienne E, et al. [Antiarrhythmic effects of intravenous magnesium sulfate in torsade de pointes. Apropos of 6 cases]. Arch Mal Coeur Vaiss. 1986;79(3):362-7.

102. Cheungpasitporn W, Thongprayoon C, Kittanamongkolchai W, Srivali N, Edmonds PJ, Ungprasert $P$, et al. Proton pump inhibitors linked to hypomagnesemia: a systematic review and meta-analysis of observational studies. Ren Fail. 2015;37(7):1237-41.

103. Bibawy JN, Parikh V, Wahba J, Barsoum EA, Lafferty J, Kowalski M, et al. Pantoprazole (proton pump inhibitor) contributing to Torsades de Pointes storm. Circ Arrhythm Electrophysiol. 2013;6(2):e17-9.

104. Ichihara A, Suzuki H, Saruta T. Effects of magnesium on the renin-angiotensin-aldosterone system in human subjects. J Lab Clin Med. 1993;122(4):432-40.

105. Fang X, Wang K, Han D, He X, Wei J, Zhao L, et al. Dietary magnesium intake and the risk of cardiovascular disease, type 2 diabetes, and all-cause mortality: a dose-response meta-analysis of prospective cohort studies. BMC Med. 2016;14(1):210.

106. Taveira TH, Ouellette D, Gulum A, Choudhary G, Eaton CB, Liu S, et al. Relation of Magnesium Intake With Cardiac Function and Heart Failure Hospitalizations in Black Adults: The Jackson Heart Study. Circ Heart Fail. 2016;9(4):e002698.

107. Gottlieb SS, Fisher ML, Pressel MD, Patten RD, Weinberg M, Greenberg N. Effects of intravenous magnesium sulfate on arrhythmias in patients with congestive heart failure. Am Heart J. 1993;125(6):1645-50 
108. Eichhorn EJ, Tandon PK, DiBianco R, Timmis GC, Fenster PE, Shannon J, et al. Clinical and prognostic significance of serum magnesium concentration in patients with severe chronic congestive heart failure: the PROMISE Study. J Am Coll Cardiol. 1993;21(3):634-40.

109. Angkananard T, Anothaisintawee T, Eursiriwan S, Gorelik O, McEvoy M, Attia J, et al. The association of serum magnesium and mortality outcomes in heart failure patients: A systematic review and meta-analysis. Medicine (Baltimore). 2016;95(50):e5406.
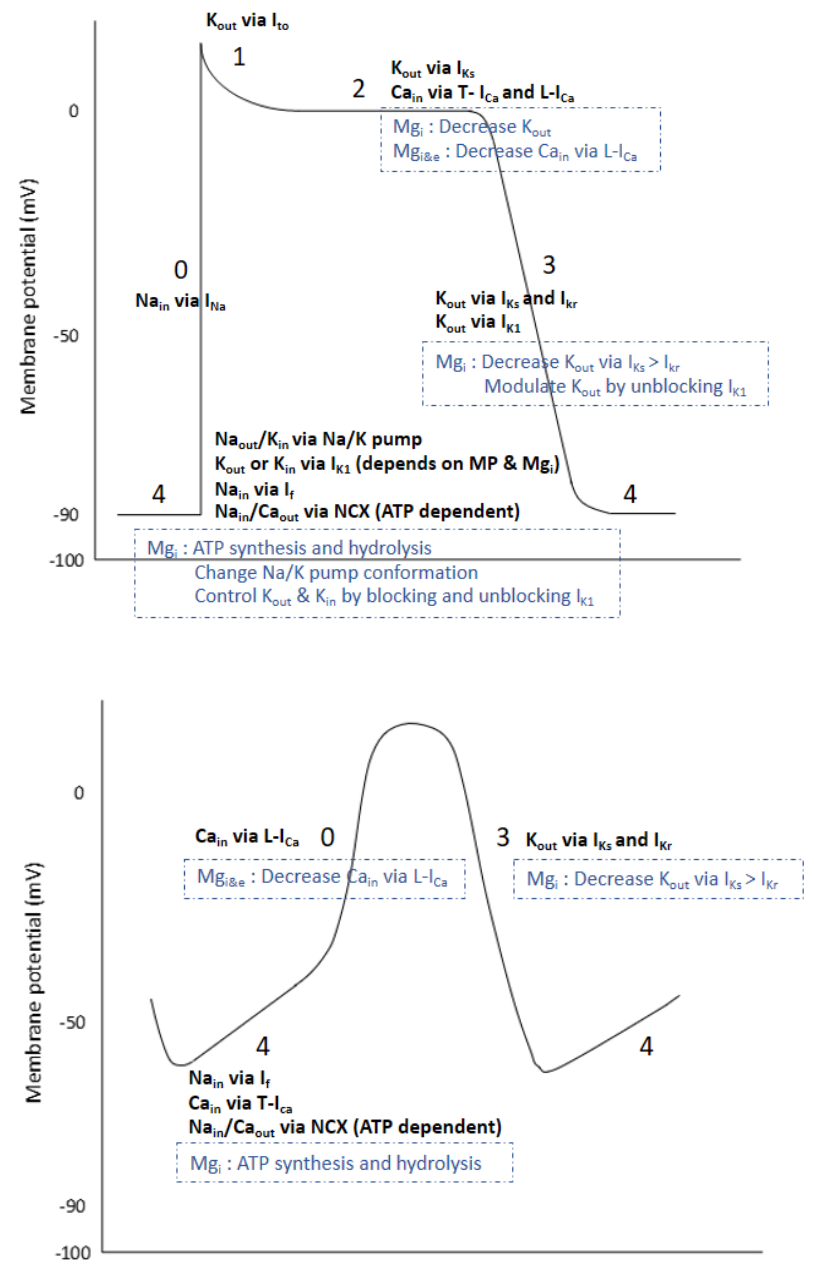

Figure 1 Contribution of magnesium on cardiac action potential

a. Cardiac myocyte action potential

b. Pacemaker cells action potential

$\mathrm{Mg}_{\mathrm{i}}=$ intracellular magnesium; $\mathrm{Mg}_{\mathrm{i} e}=$ intracellular and extracellular magnesium; $I_{\mathrm{K} 1}=$ inward rectifier potassium channel; $N C X=$ sodium-calcium exchanger; $I_{\mathrm{Na}}=$ voltage-dependent sodium channel; Ito=transient outward potassium channel; $\mathrm{I}_{\mathrm{ks}}=$ slow component of delayed rectifier potassium channel; $I_{\mathrm{Kr}}=$ rapid component of delayed rectifier potassium channel; $L-I_{C_{a}}=L$-type calcium channel; T- 
$\mathrm{I}_{\mathrm{Ca}}=\mathrm{T}$-type calcium channel; $\mathrm{I}_{\mathrm{f}}=$ "funny" pacemaker current; $\mathrm{MP}=$ =membrane potential; $\mathrm{Ca}=$ calcium; $\mathrm{K}=$ potassium; $\mathrm{Na}=$ sodium; $\mathrm{ATP}=$ adenosine triphosphate

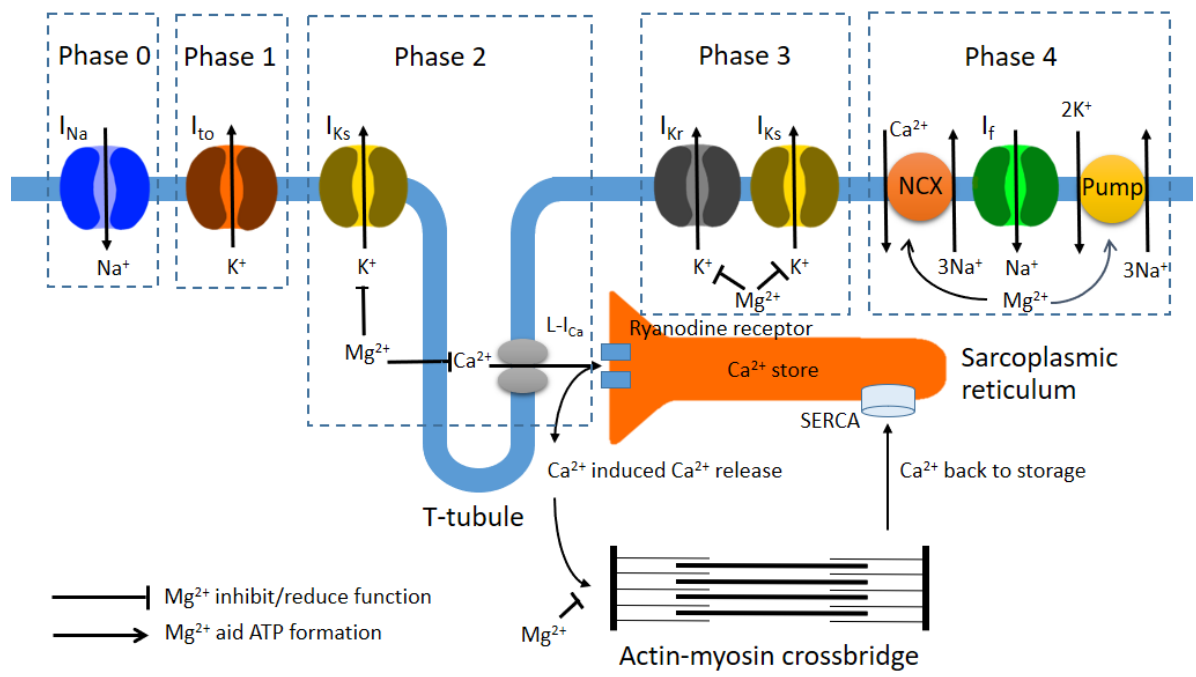

Figure 2 Ion transporters for excitation-contraction coupling in cardiac myocyte

$\mathrm{NCX}=$ sodium-calcium exchanger; $I_{\mathrm{Na}}=$ voltage-dependent sodium channel; Ito=transient outward potassium channel; $\mathrm{k}_{\mathrm{ks}}=$ slow component of delayed rectifier potassium channel; $\mathrm{k}_{\mathrm{r}}=$ rapid component of delayed rectifier potassium channel; L-I $\mathrm{C}_{\mathrm{a}}=\mathrm{L}-\mathrm{typ}$ e calcium channel; $\mathrm{I}_{\mathrm{f}}=$ "funny" pacemaker current; $\mathrm{Ca}^{2+}=$ calcium ion; $\mathrm{K}^{+}=$potassium ion; $\mathrm{Na}^{+}=$sodium; $\mathrm{Mg}^{2+}=$ magnesium ion; $\mathrm{ATP}=$ adenosine triphosphate; $\mathrm{SERCA}=$ sarcoplasmic/endoplasmic reticulum calcium ATPase

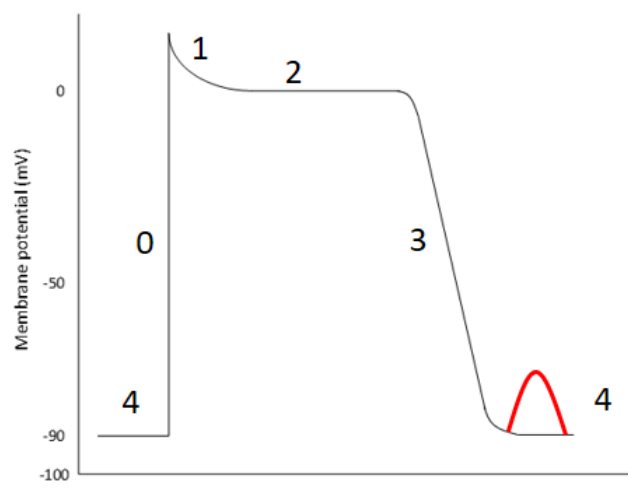




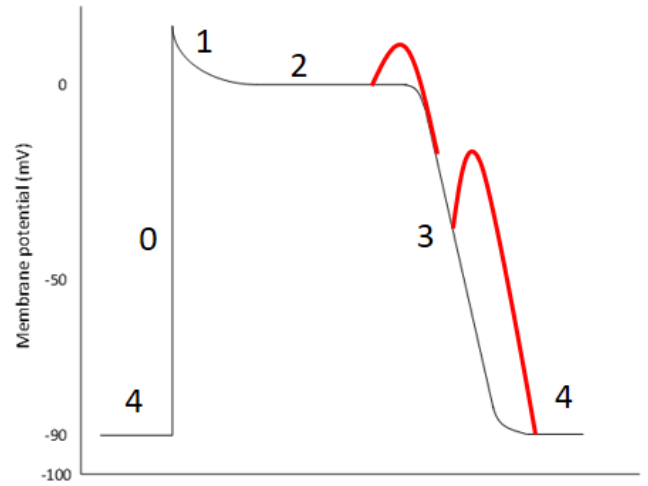

b.

Figure 3 a. Delayed afterdepolarization (DADs) : spontaneous depolarization occurs during late phase 3 or early phase 4

b. Early afterdepolarization (EADs) : spontaneous depolarization occurs during late phase 2 or phase 3

Table 1 Electrocardiographic change of abnormal serum magnesium

\begin{tabular}{ll}
\hline \multicolumn{1}{c}{ Hypomagnesemia } & \multicolumn{1}{c}{ Hypermagnesemia } \\
\hline Prolongation of PR interval & Prolongation of PR interval \\
Widening of QRS complex & Widening of QRS complex \\
Prolongation of QT interval & Prolongation of QT interval \\
Tall T wave (less severe) & Tall T wave \\
Flat T wave (more severe) & Complete heart block \\
Premature atrial and ventricular complexes & Sinus arrest \\
Atrial tachyarrhythmias & Junctional or ventricular escape rhythm \\
Ventricular arrhythmia (Torsades de pointes) & Ventricular arrhythmia \\
\hline
\end{tabular}

